\title{
3 Research Square

\section{A Novel Mutation in the Kringle IV Domain of LPA gene leading to Familial Hyperlipoproteinemia}

\section{Youran Li}

Shanghai Children's Hospital, Shanghai Jiao Tong University

\section{Xinyue Zhang}

Shanghai Children's Hospital

\section{Yizhong Wang}

Shanghai Children's Hospital

\section{Fan Gong}

Shuguang Hospital Affiliated to Shanghai University of Traditional Chinese Medicine

\section{Xiaofei Yu}

Shuguang Hospital Affiliated to Shanghai University of Traditional Chinese Medicine

Ting Zhang ( $\sim$ zhangt@shchildren.com.cn)

Children's Hospital of Shanghai https://orcid.org/0000-0001-9391-8926

\section{Research article}

Keywords: Copy number variation, Hyperlipoproteinemia, Kringle IV, Lipoprotein(a), LPA

Posted Date: December 18th, 2019

DOI: https://doi.org/10.21203/rs.2.19206/v1

License: (c) (1) This work is licensed under a Creative Commons Attribution 4.0 International License. Read Full License 


\section{Abstract}

Background This study aims to investigate the clinical characterization and causative genetic defect of a four-generation Chinese Han family with hyperlipoproteinemia. Methods The combined use of nextgeneration sequencing and qPCR technique was performed to investigate genetic pathology of familial hyperlipoproteinemia.

Results The clinical manifestations of the family members include hyperlipoproteinemia, early-onset hypertension, coronary heart disease, lipoma, cerebral infarction and even sudden death, and a novel heterozygous deletion of 3-16 exon of LPA gene was identified to be causative for the symptoms in the family.

Conclusions A novel deletion in the LPA gene was identified in a Chinese family associated with hyperlipoproteinemia, which expands the spectrum of the LPA mutation and its associated phenotype. Keywords Copy number variation; Hyperlipoproteinemia; Kringle IV; Lipoprotein(a); LPA;

\section{Background}

Coronary artery disease (CAD) has a wide range of clinical manifestations, from asymptomatic to stable coronary disease and acute coronary syndrome $[1,2]$. Hyperlipoproteinemia $[L p(a) \geq 0.3 \mathrm{~g} / L]$ has been recognized as one of the strongest risk factors for coronary heart disease [3-5]. Lp(a) consists of a single large apolipoprotein(a) [apo(a)] which attached covalently to the apolipoprotein B moiety of a cholesterolrich low-density lipoprotein (LDL) cholesterol particle [1]. The biological function of $L p(a)$ involves interfering with plasminogen activation and its atherogenic potential serving as a lipoprotein particle after receptor-mediated uptake [2]. LPA, the gene coding for apo(a), located on chromosome 6q25-6q26, explains more than $90 \%$ of the $L p(a)$ variance and it genetically determines the circulating $L p(a)$ level [2]. $\mathrm{Lp}(\mathrm{a})$ concentration has been reported to be largely determined by genetic variation within the LPA locus, including both SNVs (single nucleotide variants) and CNVs (copy number variations) [6]. LPA gene consists of ten homologous Kringle IV domains, Kringle IV types 1 and 3-10 occur only once in every apo(a) gene, while the copy number of Kringle IV types 2 is variable among individuals, and this copy number variation which represents the size polymorphism of $L p(a)$ is of pathological significance [7]. It has been reported that genetic diversity at the LPA locus, including the SNPs rs 10455872 and rs3798220, is associated with raised plasma concentrations of $L p(a)$ and incident cardiovascular disease [8]. In the present study, a novel genetic mutation in the Kringle IV domain of LPA gene was identified in a Chinese family which causes familial Hyperlipoproteinemia and associated symptoms.

\section{Methods}

The proband (III:1) (Fig. 1.) aged 50 was found to have hypertension for 2 years and also hyperlipoproteinemia with the maximum Lp(a) level up to 2,100 $\mathrm{mg} / \mathrm{L}$ for 1 year before suffering cerebral infarction at 46 years old. The family history investigation showed that there were 6 other affected 
individuals in this Chinese Han four-generation family. Family members successively went through a series of diseases because of abnormal Lp(a) concentration.

Genetic analysis of the proband was performed using next-generation sequencing with a panel covering 446 cardio-cerebrovascular diseases related genes followed by multiple lines of bioinformatics analysis (AmCare Genomics Lab). Additionally, the qPCR technique was used to detect and analyze the sitespecific variation in other 15 family members including II, III and IV generations. Similarly, the result reveled a heterozygous deletion of 3-16 exon of LPA gene in 12 of the other family members and 4 of them have had pre-existing symptoms.

\section{Results}

With a high concentration of plasma $\operatorname{Lp}(\mathrm{a})$ as the common clinical manifestations, the family members suffered different hyperlipoproteinemia-associated diseases in terms of severity: the grandmother of the proband (I:1) had sudden death; her mother (II:1) was found to have hypertension at 40 years old and suffered sudden death at 73 years old; the maternal aunt of the proband (II:3) aged 73 had early-onset hypertension and heart disease, (II:5) aged 69 had heart disease and was diagnosed with large recurrent lipoma on the outer left thigh; her brother (III:3) aged 49 and her sister (III:8) aged 45 were diagnosed with coronary heart disease with elevated $L p(a)$ around 500 to $800 \mathrm{mg} / \mathrm{L}$. There was no other diseases or abnormalities in all the affects.

A novel heterozygous deletion of 3-16 exon of LPA gene was detected in the proband (Table 1.). This copy number variation has not been reported in the related clinical cases, and the mutation is located in the Kringle IV area of LPA gene which has been reported to be associated with Lp(a) concentration in plasma. So far, the frequency of this mutation is extremely low in the population genetic database and the mutation occurs in the Kringle IV region which plays an important role in functional activity of the protein. Further analysis revealed that the amino acid sequences of this region among different species are highly conserved, which further indicate the important role of Kringle IV region and the mutation in this region may therefore impair the protein function and cause related diseases.

Table 1

Genetic features of the identified pathogenic variant

\begin{tabular}{|lllll|}
\hline $\begin{array}{l}\text { Gene } \\
\text { name }\end{array}$ & $\begin{array}{l}\text { Hereditary } \\
\text { mode }\end{array}$ & HG19 location & Transcript & $\begin{array}{l}\text { Nucleotide and amino acide } \\
\text { changes }\end{array}$ \\
\hline LPA & MU & $\begin{array}{lll}\text { chr6: } 1610332594- \\
161067427\end{array}$ & $\begin{array}{l}\text { NM- } \\
005577\end{array}$ & 3-16 exon deletion \\
\hline
\end{tabular}

\section{Discussion}

$\mathrm{Lp}(\mathrm{a})$ has been regarded as an independent risk factor for coronary heart disease. It has also been recommended to screen for elevated lipoprotein(a) concentration in patients with moderate or high-risk 
coronary heart disease, and available data increase priority for investigation of $L p(a)$ as a potential therapeutic target [9-10]. In the present study, part of the four-generation Chinese Han family members successively went through early-onset hypertension, coronary heart disease, lipoma, cerebral infarction and even sudden death with a common clinical manifestation of elevated $L p(a)$ concentration in plasma. Furthermore, atherogenic lipoprotein has also been reported to shed light on its role in development and pathogenesis of not only cardiovascular diseases but also hypertension [11]. The association of multiple lipomas with increased high-density lipoprotein (HDL)-cholesterol and $L p(a)$ concentration has been reported, although the specific mechanism for this correlation is still unclear [12-14]. Low-density lipoprotein (LDL) is independently correlated with the occurance of cerebral infarction and might be a risk factor for stroke [15]. Lp(a) has been considered as an LDL-like particle but its metabolism is different from LDL. Currently, there are clear relationships between risk of cerebral infarction and high Lp(a) concentration in plasma [16]. There is also evidence of a sustained and independent association between $L p(a)$ levels and the risk of sudden cardiac death [17]. These evidences, together with our findings, strongly support the elevated lipoprotein(a) concentration as an effective indicator not only for coronary heart disease but also for other related diseases, and making early intervention in terms of lipoprotein(a) concentration would be conducive to prevent the occurrence or deterioration of associated clinical manifestations.

\section{Conclusions}

In conclusion, the clinical manifestations of a four-generation Chinese Han family with hyperlipoproteinemia was analyzed, and a novel deletion of LPA gene was identified as the causal role for the clinical abnormalities in the patients. This study expands the spectrum of the LPA mutation and its associated phenotype. The combined use of next-generation sequencing and GPCR technique is proved to be an effective approach to investigate genetic pathology of familial hyperlipoproteinemia or other familial diseases.

\section{Declarations}

\section{Ethics approval and consent to participate}

Written informed consent for the presentation of this study was obtained from all individual participants included in the study. The study was approved by the IRB of Shuguang Hospital Affiliated to Shanghai University of Traditional Chinese Medicine (Reference numbers: 2014-368-64-01).

\section{Consent for publication}

An informed written consent for publication of the participants clinical details was obtained from each of the participants.

\section{Availability of data and materials}


The datasets used and analysed during the current study available from the corresponding author on reasonable request.

\section{Competing interests}

The authors declare that they have no competing interests.

\section{Funding}

This study was supported by grants from the National Natural Science Foundation of China (grant number 81870373), the Shanghai Hospital Development Center New Frontier Technology Joint Research Project (grant number SHDC12017115), the Shanghai Municipal Commission of Health and Family Planning Key Project (2017ZZ02019), and the Shanghai Science and Technology Committee Project (14401970300). The funders had no role in study design, data collection and analysis, decision to publish, or preparation of the manuscript.

\section{Authors' contributions}

$Y L, X Z, Y W$ drafted the manuscript. $F G, X Y, T Z$ recruited, acquired, analyzed and interpreted the data. TZ and $X Y$ supervised the management of the study and approved the manuscript. All authors read and approved the final manuscript.

\section{Acknowledgments}

The authors thank the patients and their family members for their cooperation in this study. The authors are grateful to AmCare Genomics Lab and Jing Wang, Dr.

\section{Abbreviations}

$\operatorname{Lp}(\mathrm{a})$

Lipoprotein(a)

LDL

Low-density lipoprotein

apo(a)

Apolipoprotein(a)

CAD

Coronary artery disease

SNVs

Single nucleotide variants

CNVs

Copy number variations

\section{References}


1.

Kraft HG, Köchl S, Menzel HJ, Sandholzer C, Utermann G. The apolipoprotein(a) gene: a transcribed hypervariable locus controlling plasma lipoprotein(a) concentration. Hum Genet. 1992. doi:10.1007/bf00220066.

2.

Zhijun W, Haihui S, Yanjia C, Jing T, Yan L, Qiujing C, Lin L, Wei J. Copy number variation of the lipoprotein(a) (LPA) gene is associated with coronary artery disease in a southern Han Chinese population. Int J Clin Exp Med. 2014;7 suppl 10:3669-77.

3.

Danesh J, Collins R, Peto R. Lipoprotein(a) and coronary heart disease. Meta-analysis of prospective studies. Circulation. 2000;102:1082-5.

4.

Ohira T, Schreiner PJ, Morrisett JD, Chambless LE, Rosamond WD, Folsom AR. Lipoprotein (a) and incident ischemic stroke: the Atherosclerosis Risk in Communities (ARIC) study. Stroke. 2006. doi:10.1161/01.STR.0000222666.21482.b6.

5 .

Kollerits B, Auinger M, Reisig V, Kästenbauer T, Lingenhel A, Irsigler K, Prager R, Kronenberg F. Lipoprotein(a) as a predictor of cardiovascular disease in a prospectively followed cohort of patients with type 1 diabetes. Diabetes Care. 2006. doi:10.2337/dc06-0546.

6.

Hegele RA, Breckenridge WC, Brunt JH, Connelly PW. Genetic variation in factor VII associated with variation in plasma lipoprotein(a) concentration. Arterioscler Thromb Vasc Biol. 1997. doi:10.1161/01.atv.17.9.1701.

7.

Parson W, Kraft HG, Niederstätter H, Lingenhel AW, Köchl S, Fresser F, Utermann G. A Common Nonsense Mutation in the Repetitive Kringle IV-2 Domain of human apolipoprotein(a) Results in a Truncated Protein and Low Plasma Lp(a). Hum Mutat. 2004. doi:10.1002/humu.20101.

8.

Clarke R, Peden JF, Hopewel,I JC, Kyriakou T, Goel A, et al. Genetic variants associated with Lp(a) lipoprotein level and coronary disease. N Engl J Med. 2009. doi:10.1056/NEJMoa0902604.

9.

Emerging Risk Factors Collaboration. Erqou S, Kaptoge S, Perry PL, Di Angelantonio E, et al. Lipoprotein(a) concentration and the risk of coronary heart disease, stroke, and nonvascular mortality. 2009; doi: 10.1001/jama.2009.1063.

10.

Nordestgaard BG, Chapman MJ, Ray K, Borén J, et al. Lipoprotein(a) as a cardiovascular risk factor: current status. 2010; doi:10.1093/eurheartj/ehq386.

11.

Oravec S, Dukat A, Gavornik P, Caprnda M, Kucera M, Ocadlik I. Contribution of the atherogenic lipoprotein profile to the development of arterial hypertension. Bratisl Lek Listy. 2011;112(suppl 1):4-7. 
12.

Freiberg RA, Air GW, Glueck CJ, Ishikawa T, Abrams NR. Multiple intraosseous lipomas with type-IV hyperlipoproteinemia. A case report. J Bone Joint Surg Am. 1974;56(suppl 8):1729-32.

13.

Deiana L, Pes GM, Carru C, Campus GV, Tidore MG, Cherchi GM. Extremely high HDL levels in a patient with multiple symmetric lipomatosis. Clin Chim Acta. 1993. doi:10.1016/0009-8981(93)90070-k.

14.

Musaad S, Robertson K, Clarke MW, Hooper AJ, French G, Chiu W, Burnett JR. ..Extreme hyperalphalipoproteinaemia in a patient with a solitary paraspinal lipoma. Ann Clin Biochem. 2010. doi:10.1258/acb.2009.009168.

15.

Cure MC, Tufekci A, Cure E, Kirbas S, Ogullar S, Kirbas A, Unal H, Yuce S, Cakmak S. Low-density lipoprotein subfraction, carotid artery intima-media thickness, nitric oxide, and tumor necrosis factor alpha are associated with newly diagnosed ischemic stroke. Ann Indian Acad Neurol. 2013.

doi:10.4103/0972-2327.120438. 2013.

16.

Mazhar Z, Hughes A, Garelnabi M. Targeting the Role of Lipoprotein (a) in Stroke. Cardiovasc Hematol Disord Drug Targets. 2017. doi:10.2174/1871529X17666170421150028.

17.

Kunutsor SK, Khan H, Nyyssönen K, Laukkanen JA. Lipoprotein(a) and risk of sudden cardiac death in middle-aged Finnish men: A new prospective cohort study. Int J Cardiol. 2016.

doi:10.1016/j.ijcard.2016.06.069.

\section{Figures}

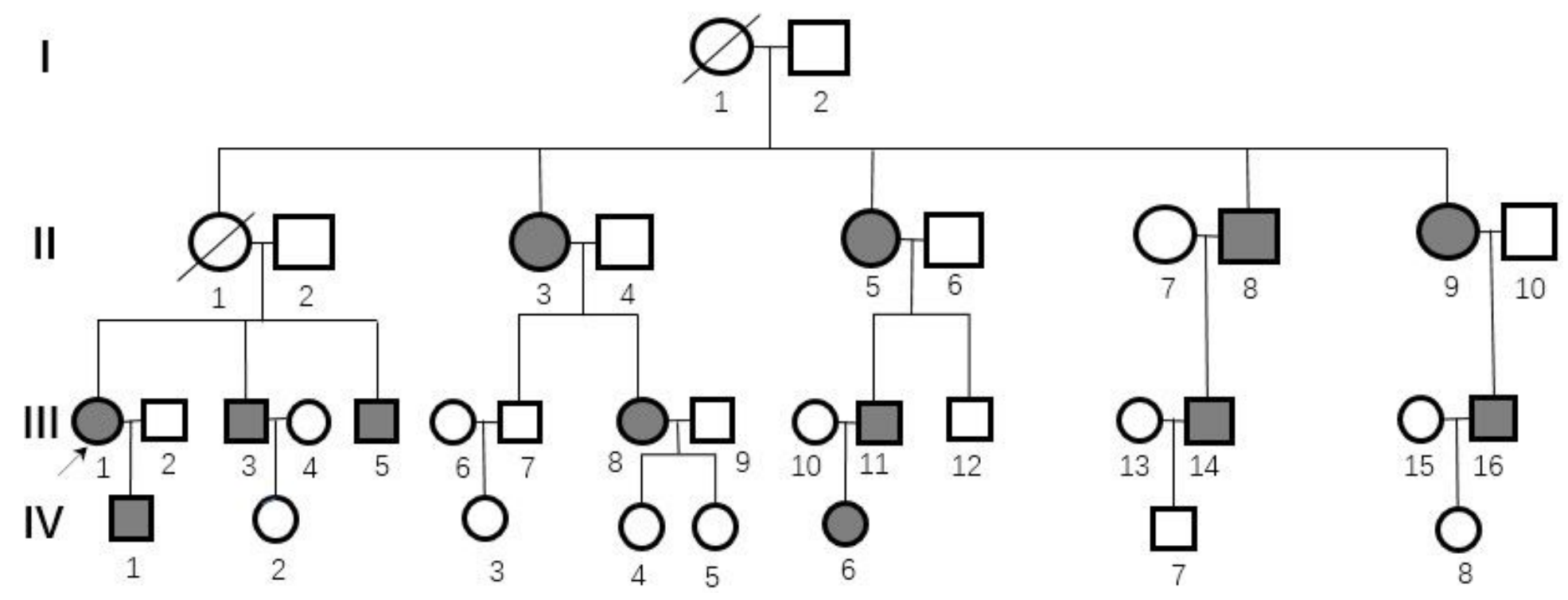

Figure 1 
Pedigree of the family with hyperlipoproteinemia. Square indicates the male and circles indicates the female, arrow points out the proband, hollow symbols and solid symbols indicate normal individuals and affected patients, respectively. 